\title{
Risk of hospitalisation and death due to bone fractures after breast cancer: a registry- based cohort study
}

\author{
Edoardo Colzani ${ }^{*}, 1,2$, Mark Clements ${ }^{1}$, Anna L V Johansson ${ }^{1}$, Annelie Liljegren ${ }^{3}$, Wei He ${ }^{1}$, Judith Brand ${ }^{1}$, \\ Jan Adolfsson ${ }^{4,5}$, Tommy Fornander ${ }^{3}$, Per Hall ${ }^{1}$ and Kamila Czene ${ }^{1}$ \\ ${ }^{1}$ Department of Medical Epidemiology and Biostatistics, Karolinska Institutet, Nobelsväg 12A, Stockholm SE-171 77, Sweden; \\ ${ }^{2}$ Department of Health Sciences, University of Milano-Bicocca, Piazza dell'Ateneo Nuovo 1, Monza 20126, Italy; ${ }^{3}$ Department of \\ Oncology and Pathology, Karolinska University Hospital, Karolinska Institutet, P.O. Box 260, Stockholm SE-171 76, Sweden; \\ ${ }^{4}$ Department of Clinical Science, Intervention and Technology, Karolinska Institutet, Stockholm SE-171 77, Sweden and ${ }^{5}$ Swedish \\ Agency for Health Technology Assessment and Assessment of Social Services, Stockholm SE-102 33, Sweden
}

Background: Bone fractures may have an impact on prognosis of breast cancer. The long-term risks of bone fracture in breast cancer patients have not been thoroughly studied.

Methods: Poisson regression was used to investigate the incidence of hospitalisation due to bone fracture comparing women with and without breast cancer based on Swedish National registers. Cox regression was used to investigate the risk of being hospitalised with bone fracture, and subsequent risk of death, in a regional cohort of breast cancer patients.

Results: For breast cancer patients, the 5-year risk of bone fracture hospitalisation was $4.8 \%$ and the 30-day risk of death following a bone fracture hospitalisation was $2.0 \%$. Compared with the general population, breast cancer patients had incidence rate ratios of 1.25 (95\% Cl: 1.23-1.28) and 1.18 (95\% Cl: 1.14-1.22) for hospitalisation due to any bone fracture and hip fracture, respectively. These ratios remained significantly increased for 10 years. Comorbidities (Charlson Comorbidity Index $\geqslant 1$ ) were associated with the risk of being hospitalised with bone fracture. Women taking aromatase inhibitors were at an increased risk as compared with women taking tamoxifen ( $\mathrm{HR}=1.48 ; 95 \% \mathrm{Cl}$ : 0.98-2.22). Breast cancer patients hospitalised for a bone fracture showed a higher risk of death ( $\mathrm{HR}=1.83 ; 95 \% \mathrm{Cl}: 1.50-2.22)$ compared with those without bone fracture.

Conclusions: Women with a previous breast cancer diagnosis are at an increased risk of hospitalisation due to a bone fracture, particularly if they have other comorbidities.

The improved survival over the past few decades has increased awareness about other health outcomes in women diagnosed with breast cancer. Bone fractures, in particular hip fractures, have a potential impact on morbidity, quality of life, and prognosis of breast cancer patients. To study the risk of bone fracture after a breast cancer diagnosis is of particular clinical relevance given that osteoporosis is common in postmenopausal women (Bliuc et al, 2009).

Breast cancer treatment influences risk of bone fracture through different mechanisms. Adjuvant treatment in particular may affect calcium and bone metabolism possibly leading to an increased risk (Becker et al, 2012). Hormonal therapy with aromatase inhibitors has in fact been found to be associated with risk of bone fracture in contrast to tamoxifen that has shown a protective effect (Breast Cancer Trials Committee, 1987; Fisher et al, 1989; Rutqvist et al, 2007; Cooke et al, 2008; Amir et al, 2011; Edwards et al, 2011). Other types of oncologic adjuvant treatment may also have potential negative effects on the skeleton independent of sex hormones (Pfeilschifter and Diel, 2000; Arnold, 2013). In addition,

*Correspondence: Dr E Colzani; E-mail: edo.colzani@gmail.com

Received 3 March 2016; revised 18 August 2016; accepted 11 September 2016; published online 4 October 2016

(c) 2016 Cancer Research UK. All rights reserved 0007-0920/16 
increasing evidence is suggesting that bone marrow microenvironment is involved in the metastatic process (Benoy et al, 2006; Semesiuk et al, 2013). Finally, it was shown that bone-targeted drugs, like bisphosphonates, may reduce skeletal metastasis and improve survival (Wong et al, 2012; Coleman et al, 2014). For all these reasons, bisphosphonates are currently administered to some patients in parallel to the adjuvant treatment in order to reduce the risk of bone metastasis and to strengthen the bone tissue (Van Poznak et al, 2011; Rizzoli et al, 2012).

An increased risk of bone fractures in women diagnosed with breast cancer has been shown but the duration and the magnitude of this risk have not been clarified (Peppone et al, 2014). It is also not clear whether there is an increased risk of fractures among women with breast cancer independent of treatment and whether tumour characteristics and comorbidities influence the risk. It is also of outmost clinical importance to assess the risk of dying after being hospitalised with bone fracture in women with a previous breast cancer diagnosis.

The aim of this study is to investigate, in women with a breast cancer diagnosis, the risk of being hospitalised with a bone fracture and possible effects of patient and tumour characteristics at breast cancer diagnosis as well as treatment. In addition, we study the risk of dying following a hospitalisation due to a bone fracture.

\section{MATERIALS AND METHODS}

Study cohorts. Two different cohorts of Swedish women were used to address the research questions.

The first, national cohort, comprised data extracted from a national database. Individuals from the Swedish Total Population Register were linked by personal identification numbers to the National Cancer Register (Mattsson and Wallgren, 1984; Barlow et al, 2009), the National Cause of Death Register (Rutqvist, 1985), and the Inpatient Register (Ludvigsson et al, 2011). The National Cancer Register reports all records for each cancer diagnosis made in Sweden coded through the Seventh version of International Classification of Diseases (ICD-7) since 1958. The National Cause of Death Register collects all causes of death in Sweden that are mandatorily reported since 1952. The Inpatient Register reports hospitalisations in all Sweden since 1987, coded through the Ninth and Tenth versions of International Classification of Diseases (ICD-9 and ICD-10), and has nationwide coverage. This national cohort was restricted to women aged $\geqslant 45$ years for the calendar period 1990-2010.

The second, regional cohort, included data extracted from the Stockholm Breast Cancer Register, a population-based register comprising all women diagnosed with invasive breast cancer in the Swedish counties of Stockholm and Gotland from 1976, linked to other national registers as described for the first cohort. The register has $\sim 99 \%$ completeness for women aged $<75$ years at diagnosis and provides good information about tumour characteristics at breast cancer diagnosis and treatment (Mattsson et al, 1985). From this register we extracted information of all women with a first invasive breast cancer diagnosis in the period 1990-2006 and $<75$ years at diagnosis. Of the $n=14188$ remaining observations we further excluded women with stage IV disease $(n=264)$, those with tumours $<1 \mathrm{~mm}(n=52)$, those who received neoadjuvant treatment $(n=802)$, and those who did not receive any breast cancer surgery $(n=220)$. A total of $n=12850$ women were left for the analysis. We also retrieved information on comorbid conditions before diagnosis through the Inpatient Register and summarised this into the Charlson Comorbidity Index (CCI) score, a widely used methodology for grouping comorbid conditions (Charlson et al, 1987; Quan et al, 2005).
In an additional linkage based on the same registries as the regional cohort, women diagnosed with breast cancer between 2005 and 2008 were further linked to the Swedish Prescribed Drug Register in order to investigate the potential effect of type of adjuvant hormone treatment on future fractures. The Swedish Prescribed Drug Register contains information on all prescribed medicines dispensed by Swedish pharmacies since 1 July 2005, including dates of prescription and dispense, number of defined daily doses, and classification of drugs according to the Anatomical Therapeutic Chemical (ATC) Classification System. This register is reported to be nationwide complete, with $<0.3 \%$ of data entries with missing Personal Identification Numbers (Wettermark et al, 2007). Through this linkage, we identified 2551 patients diagnosed with breast cancer between 2005 and 2008 who initiated adjuvant hormone therapy with at least one prescription of tamoxifen (ATC codes L02BA01) or aromatase inhibitors (ATC codes L02BG) and were followed until end of 2012.

ICD codes and events. Breast cancer diagnoses were based on ICD-7 code 170. The hospitalisation events were defined as: hospitalisation after breast cancer diagnosis due to bone fracture, excluding fractures of the skull and of the neck (ICD-9 codes 805-829, 733.0, and 733.93-98, and ICD-10 codes S22, S32, S42, S52, S62, S72, S82, S92, T02, T08, T10, T12, T14.2, and M80); and hospitalisation after breast cancer diagnosis due to hip fracture (ICD-9 code 820, and ICD-10 codes S72.0, S72.1, and S72.2). All hospitalisation events were defined based on the main diagnosis of hospitalisation. The death events were categorised using the underlying cause of death.

Ethics. The study was entirely based on data from Swedish health and population registers and was approved by the Ethical Review Board at Karolinska Institutet, Stockholm, Sweden (Dnr 2011/1898 32; Dnr 2007/821-31/3; Dnr 2012/217-32/2; Dnr 2014/1401-32). No contact was made with the study participants, data were analysed anonymously, and thus informed consent was not obtained. This exception from informed consent was confirmed by the ethical committee.

Statistical analysis. In the national cohort, we first compared the incidence of first recorded bone fracture-related hospitalisations in women with breast cancer with that in the general female population resident in Sweden between 1990 and 2010. For women with breast cancer not previously hospitalised for fracture, the person-time was split by attained age, attained calendar period, and time since cancer diagnosis. For women without breast cancer not previously hospitalised for fracture, the person-time was split by attained age and attained calendar period. The follow-up time was calculated as the date of first recorded fracture (for an event), death, emigration, or 31 December 2010, whichever came first. The cohort was analysed using Poisson regression, modelling the hospitalisation rate using attained age, attained calendar period, and interaction between breast cancer status and time since breast cancer diagnosis. For flexible model specification, we used generalised additive models with thin plate splines for the smoothers. We adjusted for a two-dimensional thin plate spline for attained age and attained calendar period. To calculate the absolute risks in breast cancer patients, the 1- and 5-year risks of bone fracture hospitalisation were calculated for cancer diagnoses during 2005-2010, and the 30-day and 1-year risk of death following a bone fracture hospitalisation were calculated for hospitalisations during 2005-2010. For women from the national population excluding the breast cancer patients, the incidence were age standardised to the person-time distribution for the breast cancer patients, and the mortality rates were age standardised to the person-time distribution for the breast cancer patients hospitalised for a bone fracture. The data extraction was performed with SAS 9.4 (SAS Institute Inc., Cary, NC, USA); 
the generalised additive models used mgcv package (version 1.7) in R 3.0 (R Core Team, 2013).

In the regional cohort comprising only women with a previous breast cancer diagnosis, follow-up started at date of breast cancer diagnosis and was continued until date of first fracture event, death, first distant metastasis, or 31 December 2006, whichever came first. Hazard ratios (HRs) of fracture rates (or death rates depending on the analysis) were estimated using Cox regression with time since diagnosis as the underlying time scale. The proportional hazard assumption was tested using the Therneau and Grambsch test. Test for interaction between age and CCI was carried out using likelihood ratio test. We also looked at the risk of dying after hospitalisation due to a bone fracture considering three outcomes: death due to any cause, death due to breast cancer, and death due to causes other than breast cancer. In the analysis of the risk of dying after being hospitalised for a fracture, person-time was divided by time before and after first recorded hospitalisation due to a fracture. When looking at cause-specific death we also censored the analysis for the other causes of death. The analysis of the regional cohort was performed using the statistical software package STATA 12.1 (StataCorp, 2011). All tests were two sided and the level of significance was $5 \%$.

\section{RESULTS}

Of all 10866 hospitalisations due to bone fractures in the Swedish national cohort of women diagnosed with breast cancer between 1990 and 2010 and aged <75 years at diagnosis, 4008 (36.9\%) were hip fractures. Hip fractures increased over age and consequently over time since diagnosis, whereas other lower limb fractures decreased, and upper limb fractures remained stable (Supplementary Table 1). In total, 3895 (35.8\%) hospitalisations due to bone fractures occurred within 5 years since breast cancer diagnosis. Most hospitalisations due to bone fractures occurred in women aged 61-74 years at breast cancer diagnosis $(n=7364$, 67.8\%). For the breast cancer patients diagnosed during 2005-2010, the 1 -year risk of bone fracture was $0.94 \%$ (95\% CI: $0.83-1.05)$ and the 5 -year risk was $4.82 \%$ (95\% CI: $4.55-5.06)$. For the population
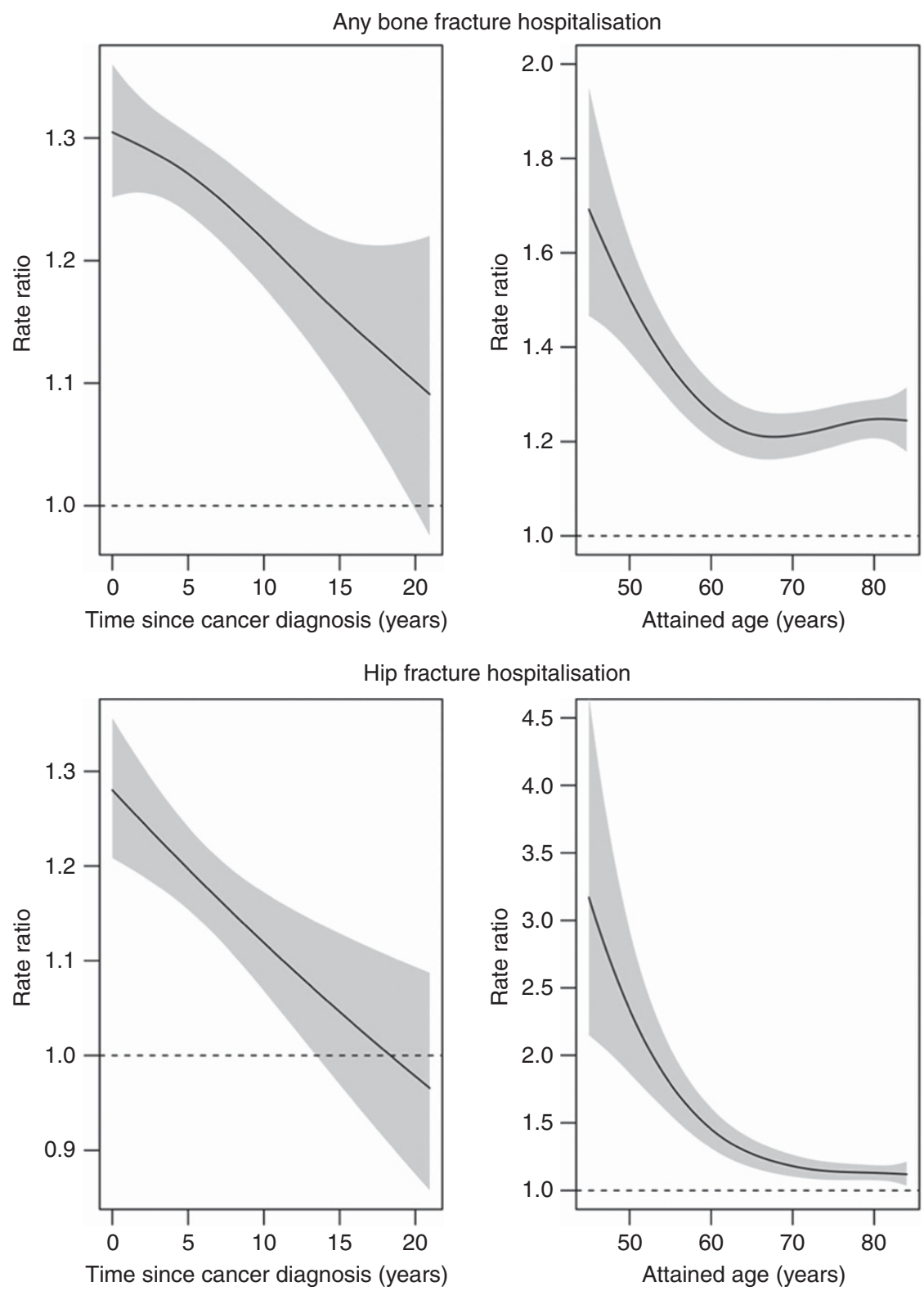

Figure 1. Rate ratios for hospitalisation due to bone fracture after breast cancer diagnosis by time since diagnosis and by attained age, Swedish national cohort, 1990-2010. 
excluding the breast cancer patients during 2005-2010, the standardised 1-year risk was $0.812 \%$ (95\% CI: 0.806-0.817) and the standardised 5-year risk was 3.97\% (95\% CI: 3.94-3.99). When looking at risk of death after bone fracture hospitalisation, for breast cancer patients with a bone fracture hospitalisation during 2005-2010, the 30-day risk of death was $1.95 \%$ (95\% CI: 1.72-2.18) and the 1-year risk of death was $18.4 \%$ (95\% CI: 17.2-19.5). For the population without breast cancer patients with a bone fracture hospitalisation, the standardised 30-day risk of death was $1.43 \%$ (95\% CI: 1.41-1.46) and the standardised 1-year risk of death was 16.1\% (95\% CI: 15.8-16.3).

The overall rate ratios for hospitalisation due to any bone fracture and for hospitalisation due to hip fracture comparing breast cancer patients with the general population was $1.25(95 \%$ CI: $1.23-1.28$ ) and 1.18 (95\% CI: 1.14-1.22), respectively, after adjusting for attained age and calendar period. These rate ratios gradually decreased over time, but remained significantly increased for 10 years since breast cancer diagnosis (Figure 1). The rate ratio of hospitalisation due to any bone fracture after breast cancer was significantly increased in all ages and decreased with increasing age, from $\sim 1.70$ at the attained age of 40 years to $\sim 1.20$ at the age of 80 years. The rate ratio of hospitalisation due to a hip fracture was also significantly increased in women of all ages, ranging from $>3.00$ at the attained age of 40 years to $\sim 1.20$ at the age of 80 years.

Table 1 shows, in the regional cohort of women with breast cancer, the frequency distribution of breast cancer patients $(n=12850)$ with hospitalisations due to any bone fracture ( $n=600)$ and with hospitalisations due to hip fracture $(n=209)$ after breast cancer diagnosis, across different characteristics. Hospitalisations due to bone fracture after breast cancer occurred more often in patients 61-74 years of age at breast cancer diagnosis (64.0\% for any bone fracture, $79.4 \%$ for hip fracture). Of the total $n=12850$ breast cancer patients included in the analysis, $n=1534$ (12\%) developed a first distant metastasis during the study period (mean follow-up time $=5.8$ years). All $1534(100 \%)$ had available information on date of first distant metastasis.

Table 2 shows the adjusted HRs of hospitalisations due to bone fracture after breast cancer diagnosis, comparing different subgroups of breast cancer patients from the regional cohort of

Table 1. First hospitalisation due to bone fracture within 10 years after breast cancer diagnosis in women from the Stockholm Breast Cancer Register's regional cohort, Stockholm-Gotland counties, 1990-2006

\begin{tabular}{|c|c|c|c|c|c|}
\hline & $\begin{array}{c}\text { Any bone } \\
\text { fracture }^{a}(\%)\end{array}$ & $\begin{array}{c}\text { No bone } \\
\text { fracture (\%) }\end{array}$ & $\underset{\text { fracture }^{\mathrm{b}}(\%)}{\mathrm{Hip}_{(}}$ & $\begin{array}{c}\text { No hip } \\
\text { fracture (\%) }\end{array}$ & Total (\%) \\
\hline \multicolumn{6}{|l|}{ Age } \\
\hline$\leqslant 50$ Years & $77(12.8)$ & $3701(30.2)$ & $12(5.7)$ & $3766(29.8)$ & $3778(29.4)$ \\
\hline 61-74 Years & $384(64.0)$ & $4497(36.7)$ & $166(79.4)$ & $4715(37.3)$ & $4881(38.00)$ \\
\hline \multicolumn{6}{|l|}{ Period } \\
\hline 1990-1994 & $260(43.3)$ & $3136(25.6)$ & $102(48.8)$ & $3294(26.1)$ & $3396(26.4)$ \\
\hline \multicolumn{6}{|l|}{ Tumour size } \\
\hline$>20 \mathrm{~mm}$ & $171(28.50)$ & $3427(27.98)$ & $62(29.7)$ & $3536(28.0)$ & $3598(28.0)$ \\
\hline$<20 \mathrm{~mm}$ & $413(68.83)$ & $8631(70.46)$ & $140(67.0)$ & $8904(70.4)$ & $9044(70.4)$ \\
\hline Missing & $16(2.67)$ & $192(1.57)$ & 7 (3.4) & $201(1.6)$ & $208(1.6)$ \\
\hline \multicolumn{6}{|c|}{ Lymph node status } \\
\hline ER positive & $392(65.3)$ & $8082(66.0)$ & $150(71.8)$ & $8324(65.9)$ & $8474(66.0)$ \\
\hline ER negative & $82(13.7)$ & $1790(14.6)$ & $25(12.0)$ & 1847 (14.6) & $1872(14.6)$ \\
\hline Missing & $126(21.0)$ & $2378(19.4)$ & $34(16.3)$ & $2470(19.5)$ & $2504(19.5)$ \\
\hline \multicolumn{6}{|c|}{ Charlson Comorbidity Index } \\
\hline 0 & $372(62.0)$ & $10264(83.8)$ & $106(50.7)$ & $10530(83.3)$ & $10636(82.8)$ \\
\hline 1 & $145(24.2)$ & 1467 (12.0) & $65(31.1)$ & 1547 (12.2) & $1612(12.5)$ \\
\hline$\geqslant 2$ & $83(13.8)$ & $484(4.0)$ & $38(18.2)$ & $529(4.2)$ & $567(4.4)$ \\
\hline Missing & $0(0.0)$ & $35(0.3)$ & $0(0.0)$ & $35(0.3)$ & $35(0.0)$ \\
\hline \multicolumn{6}{|c|}{ Adjuvant treatment $^{c}$} \\
\hline $\mathrm{CT}$ any without $\mathrm{HT}$ & $35(5.8)$ & $1369(11.2)$ & $5(2.4)$ & $1399(11.1)$ & 1404 (10.9) \\
\hline $\mathrm{HT}$ any without $\mathrm{CT}$ & $403(67.2)$ & $6943(56.7)$ & $151(72.3)$ & 7195 (56.9) & $7346(57.2)$ \\
\hline $\mathrm{HT}+\mathrm{CT}$ any & $51(8.5)$ & $2224(18.2)$ & $11(5.3)$ & $2264(17.9)$ & $2275(17.7)$ \\
\hline Other & 111 (18.5) & $1714(14.0)$ & $42(20.1)$ & $1783(14.1)$ & $1825(14.2)$ \\
\hline
\end{tabular}


Table 2. Adjusted hazard ratios ${ }^{a}$ for first hospitalisation due to bone fracture within 10 years since breast cancer diagnosis in women from the Stockholm Breast Cancer Register's regional cohort, Stockholm-Gotland counties, 1990-2006

\begin{tabular}{|c|c|c|}
\hline & $\begin{array}{c}\text { Any bone fracture } \\
\text { HR }(95 \% \mathrm{Cl})\end{array}$ & $\begin{array}{l}\text { Hip fracture } \\
\text { HR }(95 \% \mathrm{Cl})\end{array}$ \\
\hline \multicolumn{3}{|l|}{ Age } \\
\hline$<50$ Years & $0.28(0.20-0.38)^{b}$ & $0.10(0.05-0.22)^{b}$ \\
\hline $51-60$ Years & $0.42(0.33-0.53)^{b}$ & $0.24(0.15-0.39)^{b}$ \\
\hline $61-74$ Years & 1.0 (Ref.) & 1.0 (Ref.) \\
\hline \multicolumn{3}{|l|}{ Calendar period } \\
\hline 1990-1994 & $0.91(0.73-1.13)$ & $1.03(0.72-1.47)$ \\
\hline 1995-1999 & 1.0 (Ref.) & 1.0 (Ref.) \\
\hline $2000-2006$ & $0.91(0.69-1.21)$ & $0.96(0.57-1.61)$ \\
\hline \multicolumn{3}{|l|}{ Tumour characteristics } \\
\hline Tumour size $>20 \mathrm{~mm}$ & $1.21(0.98-1.50)$ & $1.26(0.89-1.78)$ \\
\hline Tumour size $<20 \mathrm{~mm}$ & 1.0 (Ref.) & 1.0 (Ref.) \\
\hline Positive lymph nodes & $1.00(0.80-1.25)$ & $1.26(0.89-1.79)$ \\
\hline Negative lymph nodes & 1.0 (Ref.) & 1.0 (Ref.) \\
\hline ER positive & 1.0 (Ref.) & 1.0 (Ref.) \\
\hline ER negative & $1.14(0.85-1.53)$ & $0.90(0.54-1.51)$ \\
\hline \multicolumn{3}{|l|}{ Charlson Comorbidity Index } \\
\hline 0 & 1.0 & 1.0 \\
\hline 1 & $1.63(1.29-2.06)^{b}$ & $2.31(1.61-3.32)^{\mathbf{b}}$ \\
\hline$\geqslant 2$ & $2.44(1.85-3.24)^{\mathrm{b}}$ & $3.01(1.95-4.64)^{\mathrm{b}}$ \\
\hline \multicolumn{3}{|c|}{ Adjuvant treatment combination ${ }^{c}$} \\
\hline $\mathrm{CT}$ any combination without $\mathrm{HT}$ & $0.98(0.68-1.40)$ & $0.41(0.12-1.37)$ \\
\hline $\mathrm{HT}$ any combination without $\mathrm{CT}$ & 1.0 (Ref.) & 1.0 (Ref.) \\
\hline $\mathrm{HT}$ and $\mathrm{CT}$ any combination & $0.98(0.63-1.50)$ & $0.97(0.47-1.97)$ \\
\hline Other & $1.04(0.70-1.54)$ & $1.01(0.65-1.57)$ \\
\hline \multicolumn{3}{|l|}{ Surgery } \\
\hline Total mastectomy & 1.0 (Ref.) & 1.0 (Ref.) \\
\hline Partial mastectomy & $0.80(0.65-0.98)^{b}$ & $0.65(0.46-0.92)^{\mathbf{b}}$ \\
\hline \multicolumn{3}{|c|}{$\begin{array}{l}\text { Abbreviations: } \mathrm{Cl}=\text { confidence interval; } \mathrm{CT}=\text { chemotherapy; } \mathrm{ER}=\text { oestrogen receptor } \\
\mathrm{HR}=\text { hazard ratio; } \mathrm{HT}=\text { hormone therapy; Ref. = reference. } \\
\mathrm{a}^{\text {a }} \text { All estimates are adjusted for all variables shown in the table. } \\
\mathrm{b}_{\text {Statistically significant at } \alpha=0.05 \text {. }} \\
{ }^{C} \text { Adjuvant treatment combinations: } \mathrm{CT} \text { any without } \mathrm{HT} \text { : any combination with or without } \\
\text { radiation therapy including chemotherapy and not including hormone therapy; } \mathrm{HT} \text { any } \\
\text { without } \mathrm{CT} \text { : any combination with or without radiation therapy including hormone therapy } \\
\text { and not including chemotherapy; } \mathrm{HT}+\mathrm{CT} \text { any: any combination with or without radiation } \\
\text { therapy including both chemotherapy and hormone therapy; Other: any combination with } \\
\text { or without radiation therapy not including chemotherapy or hormone therapy. }\end{array}$} \\
\hline
\end{tabular}

breast cancer patients. After testing for proportional hazards, we could not find any evidence of time-dependent effects, therefore only a proportional hazards analysis was performed. The HR for being hospitalised with any bone fracture or with hip fracture for women $\leqslant 50$ years old at breast cancer diagnosis was 0.28 (95\% CI: $0.20-0.38$ ) and 0.10 (95\% CI: 0.05-0.22), respectively, as compared with women 61-74 years old at breast cancer diagnosis. Calendar period at breast cancer diagnosis, tumour characteristics, and adjuvant treatment combinations were not significantly associated with the risk of hospitalisation due to bone fracture. Charlson Comorbidity Index scoring as low as one was significantly associated with the risk of hospitalisation due to any bone fracture $(\mathrm{HR}=1.63 ; 95 \% \mathrm{CI}: 1.29-2.06)$ or due to hip fracture alone $(\mathrm{HR}=2.31 ; 95 \% \mathrm{CI}: 1.61-3.32)$.

We also performed an additional analysis using a regional cohort of women with information on drug use based on The Swedish Prescribed Drug Register (Figure 2). The 5-year cumulative incidence of bone fracture for those patients treated with tamoxifen, aromatase inhibitors, or chemotherapy without hormone therapy was 3.0\% (95\% CI: $2.3 \%-4.0 \%$ ), 5.9\% (95\% CI: $4.6 \%-7.6 \%)$, and $4.1 \%$ (95\% CI: $2.5 \%-6.7 \%)$, respectively. As compared with the general population, the corresponding standardised incidence ratios for bone fractures were 0.94 (95\% CI: 0.60-1.45), 1.32 (95\% CI: 0.89-1.96), and 1.39 (95\% CI:

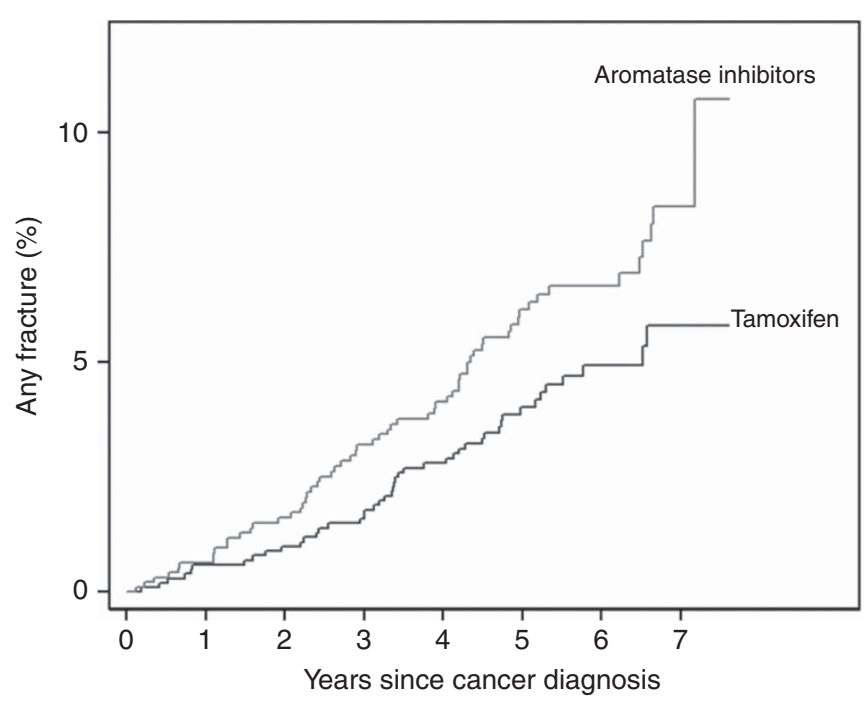

Figure 2. Risk of first hospitalisation due to bone fracture after breast cancer diagnosis by age and Charlson Comorbidity Index $(\mathrm{CCl})$ in women from the SBCR regional cohort, Stockholm-Gotland counties, 1990-2006.

Table 3. Adjusted $^{\mathrm{a}}$ hazard ratios $(95 \% \mathrm{Cl})$ for all-cause, breast cancer, and other cause of death comparing breast cancer patients with and without a hospitalisation due to a bone fracture, Stockholm Breast Cancer Register's regional cohort, Stockholm-Gotland counties, 1990-2006

\begin{tabular}{|c|c|}
\hline Causes of death & $\mathrm{HR}(95 \% \mathrm{Cl})$ \\
\hline Overall death & $1.83(1.50-2.22)^{b}$ \\
\hline Breast cancer-specific death & $0.96(0.66-1.40)$ \\
\hline Other cause of death & $2.78(2.11-3.67)^{b}$ \\
\hline \multicolumn{2}{|c|}{$\begin{array}{l}\text { Abbreviations: } \mathrm{Cl}=\text { confidence interval; } \mathrm{HR}=\text { hazard ratio. } \\
{ }^{\text {a }} \text { Model adjusted for age at diagnosis, calendar period, lymph node positivity, oestrogen } \\
\text { receptor (ER) status, tumour size, Charlson Comorbidity Index, adjuvant treatment } \\
\text { combination, and type of surgery. } \\
{ }^{b_{S}} \text { Statistically significant at } \alpha=0.05 \text {. }\end{array}$} \\
\hline
\end{tabular}

0.66-2.91), respectively. Furthermore, we found that women taking aromatase inhibitors were at higher risk of being hospitalised with a bone fracture as compared with women taking tamoxifen $(\mathrm{HR}=1.52$; 95\% CI: $1.03-2.22)$ in postmenopausal women. Similar results were found when further adjusting for age, tumour size and lymph node status ( $\mathrm{HR}=1.48 ; 95 \% \mathrm{CI}$ : 0.98-2.22).

Table 3 shows the risk of dying comparing women with or without a bone fracture in the regional cohort of breast cancer patients. After being hospitalised with a bone fracture the HR of dying due to any cause was 1.83 (95\% CI: 1.50-2.22) as compared with not being hospitalised with a bone fracture. This HR was most pronounced among women 61-74 years old at breast cancer diagnosis $(\mathrm{HR}=2.16$; 95\% CI: $1.70-2.75)$, whereas it was not significant in women $<61$ years old at breast cancer diagnosis.

\section{DISCUSSION}

Our major findings are that breast cancer patients were at an increased risk of being hospitalised with a bone fracture for at least 10 years since breast cancer diagnosis, that the presence of at least one comorbidity was associated with an increased risk of being hospitalised with a bone fracture, that patients using aromatase inhibitors were at higher risk of having a fracture compared with tamoxifen users, and that being hospitalised with a bone fracture was significantly associated with overall mortality. 
It has previously been shown that breast cancer adjuvant treatment, in particular hormonal treatment, may affect bone metabolism and bone mineral density, thus potentially influencing the risk of fractures in breast cancer patients (Breast Cancer Trials Committee, 1987; Fisher et al, 1989; Rutqvist et al, 2007; Cooke et al, 2008; Amir et al, 2011; Edwards et al, 2011; Santen, 2011; Becker et al, 2012). Still, some previous observational studies were unable to show a significantly increased risk of bone fracture in women with a previous breast cancer (Melton et al, 2012; Pawloski et al, 2013). An increased risk of bone fractures as compared with the general population was nonetheless found in other hormonedependent tumours (Melton et al, 2011; Thorstenson et al, 2012). In our study we found a significant long-term increase (up to 10 years) of the risk of hospitalisation due to bone fracture in women with a previous breast cancer diagnosis, independent of age. This risk gradually decreased during the follow-up, suggesting a potential association with treatment. The magnitude of this risk increase is however not particularly pronounced (20-25\%) and may not be considered of primary clinical relevance in a breast cancer patient; however, it is still an important risk estimation, and its potential impact on quality of life of women surviving with a previous breast cancer diagnosis should not be underestimated.

In our study, tumour characteristics were not associated with the risk of being hospitalised with a bone fracture after a breast cancer diagnosis. Comorbidities were significantly associated with the risk of being hospitalised with a bone fracture at the CCI score of 1 (Table 2). In particular, women with at least one comorbidity and aged $\leqslant 60$ years at breast cancer diagnosis showed a 10 -year cumulative incidence of bone fracture hospitalisation similar to women aged $>60$ years and without comorbidities (Figure 3).

Aromatase inhibitors, in combination with menopause and older age, can lead to bone loss and to a higher risk of fractures (Chen et al, 2009; Santen, 2011; Becker et al, 2012). On the other hand, tamoxifen was shown to be protective against the risk of osteoporosis and subsequent bone fractures in postmenopausal patients (Cooke et al, 2008; Santen, 2011). Increased risk of bone fractures in breast cancer patients treated with aromatase inhibitors as compared with patients treated with tamoxifen was seen in large clinical trials (Crivellari et al, 2008; Cuzick et al, 2010; Van Poznak et al, 2010). In our analysis, which is based on an observational study design, we also found an increased risk of bone fracture in patients treated with aromatase inhibitors as compared with tamoxifen-treated patients (Figure 2). Bisphosphonates, a class of drugs commonly administered to prevent bone loss and treat osteoporosis, have been widely used to prevent disease recurrence and mortality in breast cancer metastatic patients (Hillner et al, 2003; van Poznak et al, 2011; Wong et al, 2012). Recently, a growing body of evidence is also supporting their use in women with early breast cancer to improve prognosis (Gnant et al, 2009; Coleman et al, 2013; He et al, 2013; Early Breast Cancer Trialists' Collaborative Group (EBCTCG), 2015). In addition, the use of adjuvant denosumab has been found to reduce the risk of bone fractures in postmenopausal women treated with aromatase inhibitors (Gnant et al, 2015).

Bone fracture hospitalisations in individuals $>60$ years old is associated with an approximately two-fold increased risk of death in the first 5 years that can remain significantly elevated up to 10 years depending on type of fracture (Bliuc et al, 2009). Hip fractures in particular are also associated with potentially severe complications like deep vein thrombosis, pressure ulcers, and pulmonary embolism, whereas vertebral fractures can affect pulmonary function (Schlaich et al, 1998; Margolis et al, 2003; Anand and Buch, 2007; Nakase et al, 2009). Our findings showed an increased overall mortality in breast cancer patients following hospitalisation with bone fracture that was interestingly independent of other comorbidities and tumour characteristics (Table 3).

In this study we used large population data sources with long and complete periods of follow-up. It could be that some of the
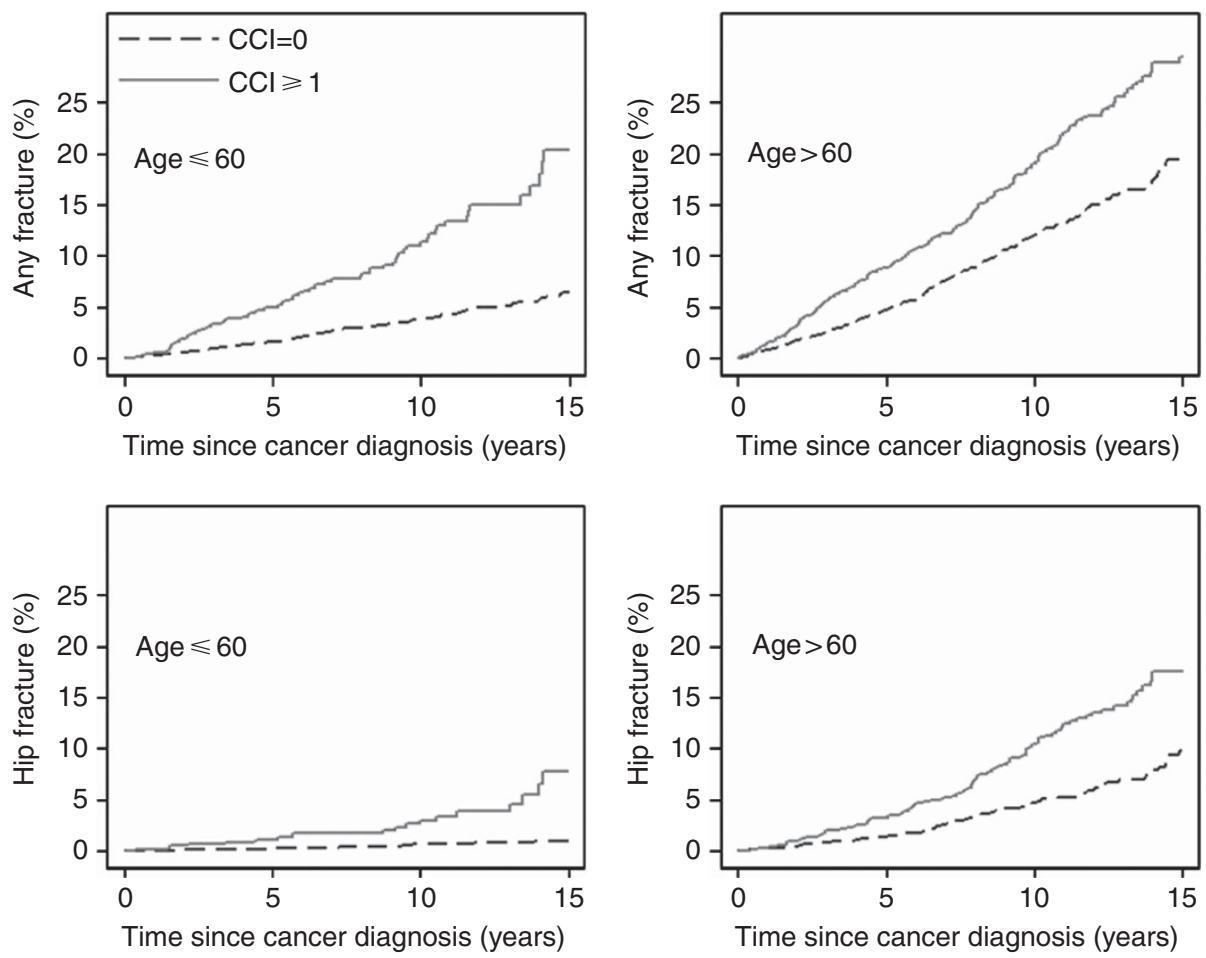

Figure 3. Risk of first hospitalisation due to bone fracture by tamoxifen/aromatase inhibitors after breast cancer diagnosis in women from the SBCR regional cohort, Stockholm-Gotland counties, 2005-2008, with additional merge to the Swedish Prescribed Drug Register and follow-up until 2013. Premenopausal women, women diagnosed with distant metastases, women aged $>75$ years at diagnosis, and women with a bone fracture history before breast cancer diagnosis were excluded from this analysis. 
reported events were pathological fractures due to breast cancer metastasis, in case bone metastases were not correctly and timely reported to the register. However, in order to avoid this bias in the regional cohort analysis we censored at time of first distant metastasis; moreover, the lack of association between hospitalisation due to bone fracture and risk of breast cancer-specific death argues against this bias being pronounced. We used specific and appropriate ICD codes to retrieve data on hospitalisations due to bone fracture from the Swedish Inpatients Register, yet we cannot rule out some degree of inaccuracy in the reporting into the register. Hip fractures usually require hospitalisation, and therefore we believe that our analysis captured most such cases; however, there may be some underestimation in the number of other fractures associated with bone loss, like wrist or vertebral fractures, that can also be treated in an outpatient setting. We believe that many of the bone fractures in our study were related to bone loss given that the majority of the women were in postmenopausal age, and given that we could not find significant differences in the findings concerning hospitalisation due to any-bone fracture and due to hip fracture, with the latter being often associated with bone loss. However, one cannot rule out the presence of a certain proportion of bone fractures in absence of bone loss (e.g., frailty that was not captured by the CCI). Attribution of specific causes of death can sometimes be inaccurate, and therefore the lack of association that we found between hospitalisation due to bone fracture and death due to breast cancer should be taken with caution. Finally, in this observational study, because of the study design, we could not account for other risk factors of bone fracture, such as bone mineral density at breast cancer diagnosis, use of certain medications (e.g., corticosteroids), lifestyle, and frailty resulting from cancer and/or treatment, and for bone preserving treatment (though bisphosphonates were gradually introduced in Sweden late into the study period) (Søgaard et al, 2013; Van Hemelrijck et al, 2013; Kiderlen et al, 2014), and this may have potentially biased some of our findings.

In conclusion, in our cohort, women with breast cancer are at an increased risk of developing bone fractures. This association is particularly pronounced in fragile patients, defined as those with one or more comorbidity, including patients $\leqslant 60$ years of age at diagnosis. In this observational study, aromatase inhibitor-treated patients were at an increased risk of being hospitalised with a bone fracture compared with tamoxifen-treated patients. Finally, hospitalisation due to a bone fracture was associated with an increased risk of death.

\section{ACKNOWLEDGEMENTS}

We thank the Stockholm Breast Cancer Registry and the Stockholm Breast Cancer Group for the data made available and for the help in the data cleaning and study design phase. This work was financed by the Swedish Research Council (Grant No. 2014 -2271), Swedish Cancer Society (Grant No. CAN 2013/469), and FORTE (Grant No. 2013-0474). We also acknowledge the Swedish Initiative for research on Microdata in the Social and Medical Sciences (SIMSAM), Grant Number 80748301.

\section{CONFLICT OF INTEREST}

The authors declare no conflict of interest.

\section{AUTHOR CONTRIBUTIONS}

EC participated in the study designing and data collection, performed the statistical analysis, and drafted the manuscript.
MC and ALVJ participated in the data collection and contributed to the statistical analysis. WH and JB participated in the study design, contributed to the statistical analysis and revised the manuscript for important intellectual content. AL, JA, PH and TF conceived the study, participated in its design, and revised the manuscript for important intellectual content. KC conceived, designed, and coordinated the study and helped in drafting the manuscript. All authors read, reviewed, and approved the final manuscript.

\section{REFERENCES}

Amir E, Seruga B, Niraula S, Carlsson L, Ocaña A (2011) Toxicity of adjuvant endocrine therapy in postmenopausal breast cancer patients: a systematic review and meta-analysis. J Natl Cancer Inst 103(17): 1299-1309.

Anand S, Buch K (2007) Post-discharge symptomatic thromboembolic events in hip fracture patients. Ann R Coll Surg Engl 89(5): 517-520.

Arnold PM (2013) Radiation-induced fracture. J Neurosurg Spine 18(5): 428-429.

Barlow L, Westergren K, Holmberg L, Talbäck M (2009) The completeness of the Swedish Cancer Register: a sample survey for year 1998. Acta Oncologica 48(1): 27-33.

Becker T, Lipscombe L, Narod S, Simmons C, Anderson GM, Rochon PA (2012) Systematic review of bone health in older women treated with aromatase inhibitors for early-stage breast cancer. J Am Geriatr Soc 60(9): 1761-1767.

Benoy IH, Elst H, Philips M, Wuyts H, Van Dam P, Scharpé S, Van Marck E, Vermeulen PB, Dirix LY (2006) Real-time RT-PCR detection of disseminated tumour cells in bone marrow has superior prognostic significance in comparison with circulating tumour cells in patients with breast cancer. Br J Cancer 94(5): 672-680.

Bliuc D, Nguyen ND, Milch VE, Nguyen TV, Eisman JA, Center JR (2009) Mortality risk associated with low-trauma osteoporotic fracture and subsequent fracture in men and women. JAMA 301(5): 513-521.

Breast Cancer Trials Committee (1987) Adjuvant tamoxifen in the management of operable breast cancer: the Scottish Trial, Scottish Cancer Trials Office (MRC), Edinburgh. Lancet 2(8552): 171-175.

Charlson ME, Pompei P, Ales KL, MacKenzie CR (1987) A new method of classifying prognostic comorbidity in longitudinal studies: development and validation. J Chronic Dis 40(5): 373-383.

Chen Z, Maricic M, Aragaki AK, Mouton C, Arendell L, Lopez AM, Bassford T, Chlebowski RT (2009) Fracture risk increases after diagnosis of breast or other cancers in postmenopausal women: results from the Women's Health Initiative. Osteoporos Int 20(4): 527-536.

Coleman R, Body JJ, Aapro M, Hadji P, Herrstedt J (2014) Bone health in cancer patients: ESMO Clinical Practice Guidelines. Ann Oncol 25(Suppl 3): iii124-iiil37.

Coleman R, de Boer R, Eidtmann H, Llombart A, Davidson N, Neven P, von Minckwitz G, Sleeboom HP, Forbes J, Barrios C, Frassoldati A, Campbell I, Paija O, Martin N, Modi A, Bundred N (2013) Zoledronic acid (zoledronate) for postmenopausal women with early breast cancer receiving adjuvant letrozole (ZO-FAST study): final 60-month results. Ann Oncol 24(2): 398-405.

Cooke AL, Metge C, Lix L, Prior HJ, Leslie WD (2008) Tamoxifen use and osteoporotic fracture risk: a population-based analysis. J Clin Oncol 26(32): 5227-5232.

Crivellari D, Sun Z, Coates AS, Price KN, Thürlimann B, Mouridsen H, Mauriac L, Forbes JF, Paridaens RJ, Castiglione-Gertsch M, Gelber RD, Colleoni M, Láng I, Del Mastro L, Gladieff L, Rabaglio M, Smith IE, Chirgwin JH, Goldhirsch A (2008) Letrozole compared with tamoxifen for elderly patients with endocrine-responsive early breast cancer: the BIG 1-98 trial. J Clin Oncol 26(12): 1972-1979.

Cuzick J, Sestak I, Baum M, Buzdar A, Howell A, Dowsett M, Forbes JF. ATAC/LATTE investigators (2010) Effect of anastrozole and tamoxifen as adjuvant treatment for early-stage breast cancer: 10-year analysis of the ATAC trial. Lancet Oncol 11(12): 1135-1141.

Early Breast Cancer Trialists' Collaborative Group (EBCTCG) (2015) Adjuvant bisphosphonate treatment in early breast cancer: metaanalyses of individual patient data from randomised trials. Lancet 386 : 1353-1361. 
Edwards BJ, Raisch DW, Shankaran V, McKoy JM, Gradishar W, Bunta AD, Samaras AT, Boyle SN, Bennett CL, West DP, Guise TA (2011) Cancer therapy associated bone loss: implications for hip fractures in mid-life women with breast cancer. Clin Cancer Res 17(3): 560-568.

Fisher B, Costantino J, Redmond C, Poisson R, Bowman D, Couture J, Dimitrov NV, Wolmark N, Wickerham DL, Fisher ER (1989) A randomized clinical trial evaluating tamoxifen in the treatment of patients with node-negative breast cancer who have estrogen-receptor-positive tumors. N Engl J Med 320(8): 479-484.

Gnant M, Mlineritsch B, Schippinger W, Luschin-Ebengreuth G, Pöstlberger S, Menzel C, Jakesz R, Seifert M, Hubalek M, Bjelic-Radisic V, Samonigg H, Tausch C, Eidtmann H, Steger G, Kwasny W, Dubsky P, Fridrik M, Fitzal F, Stierer M, Rücklinger E, Greil R. ABCSG-12 Trial Investigators, Marth C (2009) Endocrine therapy plus zoledronic acid in premenopausal breast cancer. N Engl J Med 360(7): 679-691.

Gnant M, Pfeiler G, Dubsky PC, Hubalek M, Greil R, Jakesz R, Wette V, Balic M, Haslbauer F, Melbinger E, Bjelic-Radisic V, Artner-Matuschek S, Fitzal F, Marth C, Sevelda P, Mlineritsch B, Steger GG, Manfreda D, Exner R, Egle D, Bergh J, Kainberger F, Talbot S, Warner D, Fesl C, Singer CF, Austrian Breast and Colorectal Cancer Study Group (2015) Adjuvant denosumab in breast cancer (ABCSG-18): a multicentre, randomised, double-blind, placebo-controlled trial. Lancet 386: 433-443.

He M, Fan W, Zhang X (2013) Adjuvant zoledronic acid therapy for patients with early stage breast cancer: an updated systematic review and metaanalysis. J Hematol Oncol 6(1): 80.

Hillner BE, Ingle JN, Chlebowski RT, Gralow J, Yee GC, Janjan NA, Cauley JA, Blumenstein BA, Albain KS, Lipton A, Brown S (2003) American Society of Clinical Oncology 2003 update on the role of bisphosphonates and bone health issues in women with breast cancer. J Clin Oncol 21(21): 4042-4057.

Kiderlen M, de Glas NA, Bastiaannet E, van de Water W, de Craen AJ, Guicherit OR, Merkus JW, Extermann M, van de Velde CJ, Liefers GJ (2014) Impact of comorbidity on outcome of older breast cancer patients: a FOCUS cohort study. Breast Cancer Res Treat 145(1): 185-192.

Ludvigsson JF, Andersson E, Ekbom A, Feychting M, Kim JL, Reuterwall C, Heurgren M, Olausson PO (2011) External review and validation of the Swedish national inpatient register. BMC Public Health 11: 450.

Margolis DJ, Knauss J, Bilker W, Baumgarten M (2003) Medical conditions as risk factors for pressure ulcers in an outpatient setting. Age Ageing 32: 259-264.

Mattsson B, Rutqvist LE, Wallgren A (1985) Undernotification of diagnosed cancer cases to the Stockholm Cancer Registry. Int J Epidemiol 14(1): 64-69.

Mattsson B, Wallgren A (1984) Completeness of the Swedish Cancer Register. Non-notified cancer cases recorded on death certificates in 1978. Acta Radiol Oncol 23(5): 305-313.

Melton 3rd LJ, Hartmann LC, Achenbach SJ, Atkinson EJ, Therneau TM, Khosla S (2012) Fracture risk in women with breast cancer: a populationbased study. J Bone Miner Res 27(5): 1196-1205.

Melton 3rd LJ, Lieber MM, Atkinson EJ, Achenbach SJ, Zincke H, Therneau TM, Khosla S (2011) Fracture risk in men with prostate cancer: a population-based study. J Bone Miner Res 26(8): 1808-1815.

Nakase J, Toribatake Y, Mouri Y, Seki H, Kitaoka K, Tomita K (2009) Heparin versus danaproid for prevention of venous thromboembolism after hip surgery. J Orthop Surg (Hong Kong) 17(1): 6-9.

Pawloski PA, Geiger AM, Haque R, Kamineni A, Fouayzi H, Ogarek J, Petersen HV, Bosco JL, Thwin SS, Silliman RA, Field TS (2013) Fracture risk in older, long-term survivors of early-stage breast cancer. J Am Geriatr Soc 61(6): 888-895.

Peppone LJ, Mustian KM, Rosier RN, Carroll JK, Purnell JQ, Janelsins MC, Morrow GR, Mohile SG (2014) Bone health issues in breast cancer survivors: a Medicare Current Beneficiary Survey (MCBS) study. Support Care Cancer 22(1): 245-251.

Pfeilschifter J, Diel IJ (2000) Osteoporosis due to cancer treatment: pathogenesis and management. J Clin Oncol 18(7): 1570-1593.
Quan H, Sundararajan V, Halfon P, Fong A, Burnand B, Luthi JC, Saunders LD, Beck CA, Feasby TE, Ghali WA (2005) Coding algorithms for defining comorbidities in ICD-9-CM and ICD-10 administrative data. Med Care 43(11): 1130-1139.

R Core Team (2013) R: A language and environment for statistical computing. R Foundation for Statistical Computing. R Core Team: Vienna, Austria. Available at: http://www.R-project.org/.

Rizzoli R, Body JJ, DeCensi A, Reginster JY, Piscitelli P, Brandi ML (2012) Guidance for the prevention of bone loss and fractures in postmenopausal women treated with aromatase inhibitors for breast cancer: an ESCEO position paper. Osteoporos Int 23(11): 2567-2576.

Rutqvist LE (1985) Validity of certified causes of death in breast carcinoma patients. Acta Radiol Oncol 24(5): 385-390.

Rutqvist LE, Johansson H. Stockholm Breast Cancer Study Group (2007) Long-term follow-up of the randomized Stockholm trial on adjuvant tamoxifen among postmenopausal patients with early stage breast cancer. Acta Oncol 46(2): 133-145.

Santen RJ (2011) Clinical review: Effect of endocrine therapies on bone in breast cancer patients. J Clin Endocrinol Metab 96(2): 308-319.

Schlaich C, Minne HW, Bruckner T, Wagner G, Gebest HJ, Grunze M, Ziegler R, Leidig-Bruckner G (1998) Reduced pulmonary function in patients with spinal osteoporotic fractures. Osteoporos Int 8(3): 261-267.

Semesiuk NI, Zhylchuk A, Bezdenezhnykh N, Lykhova A, Vorontsova AL, Zhylchuk VE, Kudryavets YI (2013) Disseminated tumor cells and enhanced level of some cytokines in bone marrow and peripheral blood of breast cancer patients as predictive factors of tumor progression. Exp Oncol 35(4): 295-302.

Søgaard M, Thomsen RW, Bossen KS, Sørensen HT, Nørgaard M (2013) The impact of comorbidity on cancer survival: a review. Clin Epidemiol 5(Suppl 1): 3-29.

StataCorp 2011. Stata statistical software: Release 12. StataCorp Lp: College Station, TX, USA.

Thorstenson A, Bratt O, Akre O, Hellborg H, Holmberg L, Lambe M, Bill-Axelson A, Stattin P, Adolfsson J (2012) Incidence of fractures causing hospitalisation in prostate cancer patients: results from the population-based PCBaSe Sweden. Eur J Cancer 48(11): 1672-1681.

Van Hemelrijck M, Garmo H, Michaëlsson K, Thorstenson A, Akre O, Stattin P, Holmberg L, Adolfsson J (2013) Mortality following hip fracture in men with prostate cancer. PLoS One 8(9): e74492.

Van Poznak C, Hannon RA, Mackey JR, Campone M, Apffelstaedt JP, Clack G, Barlow D, Makris A, Eastell R (2010) Prevention of aromatase inhibitorinduced bone loss using risedronate: the SABRE trial. J Clin Oncol 28(6): 967-975.

Van Poznak CH, Temin S, Yee GC, Janjan NA, Barlow WE, Biermann JS, Bosserman LD, Geoghegan C, Hillner BE, Theriault RL, Zuckerman DS, Von Roenn JH (2011) American Society of Clinical Oncology executive summary of the clinical practice guideline update on the role of bone-modifying agents in metastatic breast cancer. J Clin Oncol 29(9): 1221-1227.

Wettermark B, Hammar N, Fored CM, Leimanis A, Otterblad Olausson P, Bergman U, Persson I, Sundström A, Westerholm B, Rosén M (2007) The new Swedish Prescribed Drug Register-opportunities for pharmacoepidemiological research and experience from the first six months. Pharmacoepidemiol Drug Saf 16(7): 726-735.

Wong MH, Stockler MR, Pavlakis N (2012) Bisphosphonates and other bone agents for breast cancer. Cochrane Database Syst Rev 2: CD003474.

This work is published under the standard license to publish agreement. After 12 months the work will become freely available and the license terms will switch to a Creative Commons AttributionNonCommercial-Share Alike 4.0 Unported License.

Supplementary Information accompanies this paper on British Journal of Cancer website (http://www.nature.com/bjc) 